\title{
Quantitative Research of Water Resources Based on Sustainable Development
}

\author{
Xiaomeng Du \\ North China Electric Power University, Baoding 071000, China \\ duxiaomengmiao@163.com
}

Keywords: sustainable development, ecological footprint model, ecological deficit

\begin{abstract}
The theory of sustainable development is now widely used in various fields. This paper will quantify the water resources based on sustainable development. We use the ecological footprint model to carry on the analysis and select Shandong Province as the research object.
\end{abstract}

\section{Introduction}

There are more than one hundred the definition of sustainable development, but the most widely accepted one is put forward by World Commission on Environment and Development in1987 [1]. Sustainable development mainly includes social sustainable development, ecological sustainable development, economic sustainable development. Water resources are the content and the carrier of the material energy transfer of the ecosystem, and the function of the water resources system has an important influence on the healthy operation of the ecosystem. The research of ecological footprint of water is the basic subject of ecological sustainable development, which has great theoretical value.

\section{Ecological Footprint Model of Water Resources}

\subsection{Background}

The ecological footprint method was proposed by Rees (E. Rees William) in the early 1990s. This is a comprehensive method in the research of sustainable development. In this model, we use the concept of ecological footprint to construct the model of water resources carrying capacity and ecological footprint of water resources. The ecological footprint of water resources is used to measure the degree of sustainable utilization of water resources, which is mainly expressed by the ecological surplus and ecological deficit of water resources. In addition, in order to illustrate the relationship between water resources supply and demand, we introduce the load index of water resources.

\subsection{Assumptions}

- All of the rainfall will enter the surface water resources eventually

- The data we collected is true and reliable

- Water consumption is positively correlated with population

- The precipitation is positively correlated with the total amount of water resources

\subsection{Water Resources Carrying Capacity}

The concept of carrying capacity of water resources is accompanied with the viewpoint of sustainable development, and it is put forward on the basis of people's understanding of the sustainable development of social economy. It is an important indicator to measure the ability of water resources to maintain economic development in a region.

The total amount of water resources in a region is the amount of groundwater resources and surface water resources after deducting repeated calculation. For the maintenance of the ecological environment, the regional water resources bearing force must be deducted $60 \%$ at least. According to the above principle, we should deduct the amount of water resources used to maintain the ecological environment when we calculate the water resources carrying capacity. The formula of water resources carrying capacity can be expressed as [2]:

$$
E C=0.4 * r_{w} * \varphi_{w} *\left[W / P_{W}\right]
$$


Where $E C$ is total ecological footprint of water resources, $r_{w}$ is global balance factor of water resources, $\varphi_{w}$ is regional water resources production factor, $\mathrm{W}$ is the amount of regional water resources and $P_{W}$ is global average production capacity of water resources.

The parameter $r_{w}$ in the above formula uses 5.19 as the calculated value, which is the value of equilibrium factor of water resources identified in the WWF2002 [3]. Besides, regional water resources production factor can be calculated as this:

$$
\varphi_{w}=P / P_{W}
$$

$P$ is water yield per unit area.

\subsection{Ecological Footprint of Water Resources}

According to the description of the water resources ecological footprint, we transform the amount of consumed water resources into the production area of corresponding account, i.e., land area of water resources. Then we balance it and finally we obtain balanced values which can be compared with each other within the scope of different regions globally. The calculation model of the water resources account can be expressed by the following formula:

$$
E F=N * e c_{w}=r_{W} * \sum_{i=1}^{t}\left[W_{i} / P_{W}\right]
$$

In the above formula, $E F$ is ecological footprint of water resources consumption, $N$ is total population, $e c_{w}$ is ecological footprint of water resources per capita and $W$ is the amount of regional water resources.

We divide the water ecological footprint into the clean water ecological footprint and the polluted water ecological footprint and establish seven water resources ecological footprint secondary account, under the water resources ecological footprint.

When $\mathrm{i}=1,2,3,4,5$, the accounts are the agricultural water, industrial water, urban public water, domestic water, ecological environment water, respectively. The sum of the accounts indicates the clean water ecological footprint $\left(E F_{C}\right)$.

$$
E F_{C}=r_{W} * \sum_{i=1}^{5}\left[W_{i} / P_{W}\right]
$$

When $\mathrm{i}=6$, the account for the waste water pollution, water, said the ecological footprint of contaminated water $\left(E F_{P}\right)$.

$$
E F_{P}=r_{W} *\left[W_{6} / P_{W}\right]
$$

In the above equation, $W_{6}$ indicates the water demand of pollution dilution. It can be calculated like this:

$$
W_{6}=\left(C_{i} / C_{o}-1\right) * Q_{i}
$$

Where $C_{i}$ is concentration of pollutants in river, $C_{O}$ is concentration of pollutants to meet the requirements of water quality standards and $Q_{i}$ is substandard sewage discharge.

The ecological footprint of water resources is the sum of the ecological footprint of clean water and the ecological footprint of polluted water.

$$
E F=E F_{C}+E F_{P}
$$

The ecological surplus and ecological deficit of water resources can be expressed by following formula:

$$
E=E F-E C
$$

$E$ means the ecological deficit. If $E>0$, the water resources of this region is in the state of ecological deficit, that is, the ecological footprint of water resources is greater than the carrying capacity of water resources, indicating that the water resources in this region is in the state of unsustainable utilization. If $E<0$, the water resources of this region is in the state of ecological surplus, that is, the ecological footprint of water resources is less than the carrying capacity of water resources, indicating that the water resources in this region is in the state of sustainable utilization 


\subsection{Water Resources Load Index}

In order to illustrate the relationship between water resources supply and demand, the load index of water resources is introduced. From the point of view of social economy, the index reflects the relationship between the utilization level of regional water resources and the development of population and economy. The calculation formula is as follows [4]:

$$
c=k \sqrt{p G / W}
$$

In the above equation, $c$ is water resources load index, $p$ is population and $G$ is gross national product. $k$ is a coefficient related to rainfall.

Table 1. Classification of Load Index of Water Resources

\begin{tabular}{cccc}
\hline $\begin{array}{c}\text { Load Index of } \\
\text { Water Resources }\end{array}$ & Level & $\begin{array}{c}\text { Utilization Degree of Water } \\
\text { Resources }\end{array}$ & $\begin{array}{c}\text { Further Development and } \\
\text { Evaluation of Water } \\
\text { Resources }\end{array}$ \\
\hline \hline $5-10$ & I & $\begin{array}{c}\text { Very high, the potential is } \\
\text { not great }\end{array}$ & $\begin{array}{c}\text { Need to adjust the water } \\
\text { outside the basin } \\
\text { Difficult development } \\
\text { conditions }\end{array}$ \\
$2-5$ & II & $\begin{array}{c}\text { High, the potential is not } \\
\text { great }\end{array}$ & $\begin{array}{c}\text { Development conditions } \\
\text { medium }\end{array}$ \\
$1-2$ & III & Medium, great potential & $\begin{array}{c}\text { Development conditions } \\
\text { are relatively easy } \\
<1\end{array}$ \\
IV & V & Lower, great potential & $\begin{array}{c}\text { Development conditions } \\
\text { are easy }\end{array}$ \\
\hline
\end{tabular}

\section{The Use of Model}

According to the United Nations water shortage map, we choose Shandong Province as the research object. Shandong province is in the serious water shortage area where per capita amount is less than 500 [5].

We look for the total water resources ecological footprint of Shandong Province in 2008-2014 $[6,8]$. We also inquire about the data relating to the sewage treatment and the concentration of pollutants [6].

Based on ecological footprint model and water resources data we collected, we can calculate $E F$, $E C, E$ and $c$ in the area. Results are shown in the following table:

Table 2. The Results of Ecological Footprint Model

\begin{tabular}{ccccc}
\hline Item & $E F$ & $E C$ & $E$ & c \\
\hline \hline 2005 & 44.55 & 20.79 & 23.76 & \\
2006 & 43.58 & 19.17 & 24.41 & \\
2007 & 42.49 & 17.81 & 24.68 & \\
2008 & 41.31 & 15.13 & 26.18 & 3.25 \\
2009 & 40.36 & 13.11 & 27.25 & 4.13 \\
2010 & 40.08 & 14.22 & 25.86 & 4.07 \\
2011 & 50.71 & 16.00 & 34.71 & 3.80 \\
2012 & 49.45 & 12.62 & 36.83 & 5.52 \\
2013 & 43.19 & 13.42 & 29.76 & 5.06 \\
2014 & 40.76 & 6.83 & 33.93 & 11.93 \\
\hline
\end{tabular}

From result of the water resources ecological footprint calculation, we can see that water resources carrying capacity in Shandong Province is less than the water resources ecological footprint, i.e., is in a state of water resources ecological deficit, so we can say this region lacking of water resources the water resources can't be used sustainably. If we want to maintain the regional development, it's 
necessary to implement water introduction transfer project or else destruct local ecological system and exploit water resources overly.

The water resources load index shows that, except for 2014, the index is in the two or three level, that is, the degree of water resources utilization is moderate, indicating the utilization of water is low on account of poor infrastructure.

\section{Future Model Development}

We can refine in the regional ecological water resources carrying capacity that is to make the water utility reflected on the loading capacity of all kinds of land (such as cultivated land, grassland, water, etc.) and the sum of different types of land bearing force is the actual water resources carrying capacity of this region.

$$
E C=\sum_{i=1}^{t} W_{i}^{*} S * r_{W} * \varphi_{W}
$$

Similarly, we can also refine water resources ecological footprint of the area and the sum of a variety of different types of resources consumption required for the production area and the region is the ecological footprint of the region.

After further refinement, we can get water resources ecological footprint and water resources carrying capacity which are more in line with the actual local situation, and then we can carry out a reasonable evaluation about the local water resources load index. The model can be applied to the dynamic analysis of water resources carrying capacity in other regions, and it also can be applied to the dynamic analysis of the global water resources carrying capacity.

\section{Summary}

In ecological footprint model, we first calculate the bearing capacity of water resources. Then we consider the water resources ecological footprint which is divided into freshwater ecological footprint and polluted water ecological footprint. Next, we calculate the water resources ecological deficit or surplus, in order to determine whether the local water resources can be sustainable or not. Then we introduce the load index of water resources to determine whether the local water supply can meet the demand. Through the research of Shandong Province, we can get the conclusion that this model can be used to quantify the sustainable development of water resources. The model improved can play a guiding role in optimizing the allocation of regional water resources.

\section{References}

[1]. WCED. Our Common Future. New York: Oxford University Press, 1987

[2]. Yue Zhang. Water resources and sustainable development in China. Nanning: Guangxi science and Technology Publishing House, 2000.2(3):120- 125

[3]. Linnan Huang, Weixin Zhang, Cuiling Jiang. Calculation method of ecological footprint of water resources[J] Ecological Journal, 2008.28(3):1279-1286

[4]. Zhiming Feng, Dengwei Liu. Supply and demand balance of water resources and water resources carrying capacity in Beijing, Tianjin and Hebei[J] Journal of natural resources, 2006.21(5):689-699

[5]. Hui Luo, Jun Zhang, Chenghua Wang. Thinking on the problem of water shortage in Shandong Province [J]. Shandong water conservancy, 2002.05:6-7.

[6]. National data. [OL] Information on: http://data.stats.gov.cn/easyquery.htm?cn=E0103

[7]. Shandong statistical information network. [OL] Information on: http://www.stats-sd.gov.cn/

[8]. Shandong Environmental Status Bulletin. [OL] Available: http://xxgk.sdein.gov.cn/xxgkndbg/ 